\title{
Buoyancy-Driven Flow Excursions in Fuel Assemblies
}

$$
\text { Conf- } 950904--1
$$

by

J. E. Laurinat

Westinghouse Savannah River Company

Savannah River Site

Aiken, South Carolina 29808

P. K Paul

Westinghouse Savannah River Company

SC USA

J. D. Menna

Westinghouse Savannah River Company

SC USA

\section{MASTER}

\section{DISCLAIMER}

\begin{abstract}
This report was prepared as an account of work sponsored by an agency of the United States Government. Neither the United States Government nor any agency thereof, nor any of their employees, makes any warranty, express or implied, or assumes any legal liability or responsibility for the accuracy, completeness, or usefulness of any information, apparatus, product, or process disclosed, or represents that its use would not infringe privately owned rights. Reference herein to any specific commercial product, process, or service by trade name, trademark, manufacturer, or otherwise does not necessarily constitute or imply its endorsement, recommendation, or favoring by the United States Government or any agency thereof. The views and opinions of authors expressed herein do not necessarily state or reflect those of the United States Government or any agency thereof.
\end{abstract}

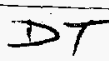

A document prepared for TTH INTERNATIONAL MEETING ON NUCLEAR REACTOR THERMAL-HYDRAULICS, NURETH-7 at Saratoga Springs from 09/10/95 - 09/15/95.

DOE Contract No. DE-AC09-89SR18035

This paper was prepared in connection with work done under the above contract number with the U.S.

Department of Energy. By acceptance of this paper, the publisher and/or recipient acknowledges the U. S. Government's right to retain a nonexclusive, royalty-free license in and to any copyright covering this paper, along with the right to reproduce and to authorize others to reproduce all or part of the copyrighted paper. 


\section{DISCLAIMER}

Portions of this document may be illegible in electronic image products. Images are produced from the best available original document. 
WSRC-MS-94-0356

\title{
BUOYANCY-DRIVEN FLOW EXCURSIONS IN FUEL ASSEMBLIES (U)
}

\author{
James E. Laurinat \\ Pran K. Paul \\ John D. Menna \\ Westinghouse Savannah River Company \\ Savannah River Technology Center \\ Aiken, SC 29802
}

\begin{abstract}
A power limit criterion was developed for a postulated Loss of Pumping Accident (LOPA) in one of the recently shut down heavy water production reactors at the Savannah River Site. These reactors were cooled by recirculating moderator downward through channels in cylindrical fuel tubes. Powers were limited to prevent a flow excursion from occurring in one or more of these parallel channels.

During full-power operation, limits prevented a boiling flow excursion from taking place. At low flow rates, during the addition of emergency cooling water, buoyant forces reverse the flow in one of the coolant channels before boiling occurs. As power increases beyond the point of flow reversal, the maximum wall temperature approaches the fluid saturation temperature, and a thermal excursion occurs.
\end{abstract}

The power limit criterion for low flow rates was the onset of flow reversal. To determine conditions for flow reversal, tests were performed in a mock-up of a fuel assembly that contained two electrically heated concentric tubes surrounded by three flow channels. These tests were modeled using a finite difference thermal-hydraulic code. According to code calculations, flow reversed in the outer flow channel before the maximum wall temperature reached the local fluid saturation temperature. Thermal excursions occurred when the maximum wall temperature approximately equaled the saturation temperature.

For a postulated LOPA, the flow reversal criterion for emergency cooling water addition was more limiting than the boiling excursion criterion for full power operation. This criterion limited powers to $37 \%$ of historical levels.

\section{Background}

Power limits for the heavy water production reactors at the Savannah River Site were set to prevent a postulated Loss of Coolant Accident (LOCA) [1]. In this design-basis accident, a line break interrupts the supply of primary coolant, causing the reactor to scram. Power limits were set to prevent a parallel channel flow excursion during the two to three seconds immediately following the scram. This flow excursion occurs when the pressure drop reaches a minimum in one flow channel due to boiling in that channel. If the coolant flow rate decreases further, the boiling diverts flow to adjacent channels, so that the affected channel dries out and undergoes a thermal excursion. The limiting criterion for a boiling excursion was a lower bound [1] to the Saha-Zuber correlation for onset of significant void generation [2]. The lower bound to the Saha-Zuber correlation, which accounts for uncertainties in the correlation, takes the form of a Stanton number, given by 


$$
\mathrm{St}=\frac{\mathrm{q}^{\prime \prime}}{\mathrm{Gc_{ \textrm {p } }}\left(\mathrm{T}_{\text {bulk }}-\mathrm{T}_{\text {sat }}\right)}=0.0065
$$

By definition, the design-basis accident must be more limiting than other postulated accidents. One of these other accidents is the Loss of Pumping Accident (LOPA), in which a line break interrupts the supply of secondary cooling water. The secondary line break trips the power to the primary AC motors for the pumps that supply primary coolant. As a result, the primary pumps coast down and the coolant flow rate gradually drops, until the emergency cooling water supply is activated. This stabilizes the coolant flow rate until the backup DC pump motors become flooded with secondary cooling water. When these motors flood, the primary pumps eventually coast to a stop. A previous analysis indicated that the most limiting condition would probably occur during the coast down of the DC pump motors [3]. This analysis used a modified Stanton number criterion based on the results of flow excursion tests conducted in a singlechannel test rig [4]:

$$
\mathrm{St}=0.0025
$$

The purpose of this study was to generate a low flow power limit criterion based on results of flow excursion tests performed in a multiple-channel test rig [5]. This test rig, called SPRIHTE, or SRS Prototypic Rig for Heat Transfer Experiments, was operated by the Savannah River Site heat transfer test facility.

\section{Description of Test Facility and Tests}

The SPRIHTE test rig, depicted in Figure 1, was prototypic of a Savannah River fuel assembly in that it consisted of concentric tubes separated by spacer ribs. Coolant flowed in the four subchannels between each pair of adjacent tubes. As the figure shows, the SPRIHTE rig contained two heated tubes and two unheated tubes, which correspond to the fuel and target tubes of a fuel assembly. The rig differed from an actual fuel assembly, however, in that the there was no outer housing. The purge channel between the outer target tube and this outer housing was replaced by two external bypass tubes located on opposite sides of the heated section.

The test rig also differed from a fuel assembly in that only the middle two tubes of the test rig, corresponding to the inner and outer fuel tubes of the reactor assembly, were heated. In a fuel assembly, both the fuel and the target tubes generate heat. The outer heater tube of the test rig received $60 \%$ of the electrical power, and the inner heater tube received $40 \%$. The heater tubes were constructed to give an axial power profile prototypic of a fuel assembly. The maximum power was located about three-quarters of the distance from the top of the heated section and was 1.43 times the average power.

Overall flow rates to the SPRIHTE rig were measured using ultrasonic and turbine flow meters; the ultrasonic flow meters measured high flow rates and the turbine flow meters measured low flow rates. Individual channel and subchannel flow rates were not metered. The rig was fully instrumented to measure subchannel coolant and heater wall temperatures. Wall and subchannel coolant temperatures were measured using thermocouples; inlet and outlet fluid temperatures were measured using resistance temperature devices (RTD's). Inlet and outlet pressures also were measured. Measurement uncertainties were $2-3 \%$ for the ultrasonic flow meters, about $2 \%$ for the turbine flow meters, $1.0^{\circ} \mathrm{C}$ or less for the thermocouples, $0.5^{\circ} \mathrm{C}$ for the RTD's, and 0.01 
atm or less for the pressure gauges [5]. In addition, the ultrasonic flow meter measurements were biased about $1 \%$ low, and the heater wall temperature measurements were biased about $1^{\circ} \mathrm{C}$ low [5]. No corrections were made to compensate for these biases.

During the tests, the flow rate and the inlet temperature were held constant and the power was increased in increments until a thermal excursion was detected by wall thermocouples. Downward flow through the test section was maintained by a centrifugal pump with a high impedance. A standpipe connected to the test rig discharge kept pressures constant.

Prior to thermal excursion, fluid thermocouple measurements indicated that there was unstable flow and flow reversal (upflow) in one of the outer subchannels. The thermal excursions always occurred in the outer channel. Unstable flow was detected by means of fluctuations of about $5^{\circ} \mathrm{C}$ in the effluent temperature. Flow reversal was said to occur when the inlet temperature exceeded any downstream temperature by $20^{\circ} \mathrm{C}$ or more. Finally, thermal excursions began when the maximum outer heater wall temperature reached $175^{\circ} \mathrm{C}$. Power was shut off at this point to prevent damage to the rig.

Tests were conducted at flow rates of $19.4,37.9$, and $56.8 \mathrm{~L} / \mathrm{min}$ and at inlet temperatures of $25^{\circ} \mathrm{C}$ and $40^{\circ} \mathrm{C}$. Only the 37.9 and $56.8 \mathrm{~L} / \mathrm{min}$ tests were analyzed, since these flow rates were within the flow range at which the limit for the ECS addition phase of the LOPA was set [3].

\section{Description and Evaluation of the Computational Model}

The SPRIHTE tests were modeled using FLOPA, a finite difference thermal-hydraulic code developed at the Savannah River Site [6]. This code was an adaptation of another Savannah River code, FLOWTRAN, which was written to compute limits for the Loss of Coolant Accident [7]. Both codes combined a three-dimensional finite difference heat conduction model for the fuel assembly tubes with a one-dimensional donor cell model for flow and heat transfer in each subchannel. From comparisons with known analytical solutions, the codes' heat conduction calculations were accurate within about $0.6 \%$ [7]. Fluid temperatures calculated by the donor cell model were offset by one-half cell length. The heated length of the SPRIHTE test rig was divided into 40 axial cells for the calculations in this study. Thus, for a typical temperature increase of $60^{\circ} \mathrm{C}$, the calculated temperatures were low by about $0.75^{\circ} \mathrm{C}$. No correction was made for this offset.

The primary sources of uncertainty in the model calculations were fluid heat transfer coefficients and friction and form loss factors for subchannel flow. Fluid heat transfer was modeled using the Sieder-Tate forced convection correlation. Friction and form loss factors were obtained from constant temperature fuel assembly hydraulic test results. Differences between nominal fuel assembly and SPRIHTE rig tube diameters were small and were therefore ignored. It was assumed that the surface roughness of the test rig tubes was the same as that of reactor assemblies and that the heated section inlet and bottom end fittings were prototypic. The use of prototypic fuel assembly dimensions and friction and form loss factors from standard fuel assembly hydraulic tests was justified through comparisons of measured and calculated fluid and wall temperatures under stable flow conditions. These comparisons showed that the use of nominal dimensions and loss factors did not have a significant adverse effect on the ability of the FLOPA code to predict these temperatures. Neither heat transfer nor fluid flow models accounted for the presence of localized boiling. 
The effect of thermocouple insertions on the flow in the inner and outer channels was assumed to be negligible, and corrections to fluid thermocouple measurements to account for fluid temperature gradients were not considered. Corrections to wall thermocouple measurements to account for thermal gradients in the heater tubes also were ignored. The wall thermocouples were centered within the heated walls. Subsequent calculations using the new limit criterion for the tests showed that the difference between the center wall and surface temperatures was $0.3^{\circ} \mathrm{C}$ at limit conditions. This difference was judged to be insignificant.

Finally, in calculations to determine a limit criterion, the test rig was modeled as a series of concentric annuli. Differences among subchannel fluid temperature measurements, particularly for the outer channel, indicated that the test rig cylinders may have been eccentric. However, no credit was taken for this apparent eccentricity in the limit criterion analysis, since the eccentricity was not measured under heated conditions.

To determine the effect of eccentricity, three-dimensional, eccentric FLOPA models were used. Three models were created. In the first, the eccentricity of the outer channel was set to match the calculated difference between the hottest and coldest subchannel in the outer channel with the measured difference. In the second, the eccentricity of the outer channel was set at its maximum value allowed by the rib tip clearance. Finally, a model was created in which the eccentricities in all three flow channels were set at the maximum values allowed by rib tip clearances. The eccentric channels were aligned in the same radial direction to maximize differences in subchannel heat transfer rates. This last model was used in LOPA limits calculations.

To verify that the FLOPA calculations accurately modeled flow and heat transfer in the test rig, calculated and measured values for subchannel fluid and heated wall temperatures were compared. In these comparisons, the eccentricity of the outer channel was adjusted to match calculated and measured differences between the hottest and coldest subchannel effluent temperatures. A separate match was performed for a heated stable flow test at each test condition. Figure 2 compares typical fluid temperature profiles for the outer channel under stable flow conditions. This figure shows that FLOPA modeled flow and heat transfer to the coolant within a range of about $5^{\circ} \mathrm{C}$. Figure 3 compares outer heater wall temperature profiles for the stable flow test condition at $56.8 \mathrm{~L} / \mathrm{min}$ and $40^{\circ} \mathrm{C}$ inlet. Again, the FLOPA model predicted measured temperatures within about $5^{\circ} \mathrm{C}$. Figure 4 compares these wall temperatures at a higher power, where flow became unstable in the outer channel. In these cases, measured wall temperatures for two of the outer subchannels are higher than the calculated temperatures, and the measured wall temperatures for the inner channel are lower than the calculated temperatures.

\section{Selection of a Limit Criterion}

To bound the results of the tests, a criterion that the wall temperature not exceed the fluid saturation temperature was used. This wall saturation temperature criterion ensures that there is no boiling along the heated walls and, therefore, a thermal excursion cannot occur. A multiplier was added to account for differences between measured and calculated subchannel flow and heat transfer rates up to the point where unstable flow and possible flow reversal occur (see the discussion of wall temperature distributions in the preceding section). The limiting fluid temperature, in degrees $\mathrm{C}$, is the product of this multiplier and the saturation temperature in degrees $\mathrm{C}$. 
Measured and computed maximum wall temperatures were compared to verify that FLOPA could accurately calculate the wall saturation temperature criterion. The maximum temperatures for these comparisons were located on the outer wall of the outer heater (the inner wall of the outer flow channel). Figures 5 through 8 illustrate these comparisons for four cases: 1) concentric flow channels, 2) an estimated eccentricity in the outer channel set to match calculated and measured differences between the hottest and coldest subchannel effluent temperatures, 3) the maximum degree of eccentricity in the outer channel allowed by the rib tip clearance, and 4) the maximum degree of eccentricity allowed by the rib tip clearance in all channels. The final case, in which the eccentricity in each flow channel is aligned so that the subchannels with the smallest cross-sectional areas are located on the same side of the assembly, was used to calculate LOPA limits. For the estimated eccentricity case (Case 2), the FLOPA model accurately predicted the maximum wall temperature at low powers under steady flow conditions, but underestimated the maximum temperatures by as much as $10^{\circ} \mathrm{C}$ at higher powers.

Limits were computed for three cases, one with concentric flow channels, one with a maximum allowable degree of eccentricity in the outer flow channel to account for the nominal rib tip clearance between the outer heater tube and the outer housing of the test section, and one with an eccentricity that matched calculated and measured temperature differences between the hottest and coldest subchannel temperatures in the outer channel. For the eccentric cases at $37.9 \mathrm{~L} / \mathrm{min}$, the FLOPA code predicted that flow reversal would occur in one subchannel of the outer channel. FLOPA did not predict that flow reversal would occur prior to measured thermal excursion conditions at $56.8 \mathrm{~L} / \mathrm{min}$.

Figures 9 through 12 illustrate the comparisons between measured conditions and calculated limits. Powers where unstable flow and flow reversal were first detected in the outer channel are noted, as are the powers where the maximum measured wall temperature first exceeded the fluid saturation temperature and where thermal excursions took place. The onsets of unstable flow, flow reversal, and thermal excursion occurred somewhere between these power levels and the next lower powers. The powers at which the maximum wall temperature equaled the saturation temperature were determined by linear interpolation of measurements at different test conditions.

These figures compare limits for the wall saturation temperature criterion with different multipliers with measured stable flow, unstable flow, flow reversal, and thermal excursion conditions and the calculated Stanton number limit. These figures make these comparisons for a concentric channel model, for the maximum outer channel eccentricity based on rib tip clearances, and for an outer channel eccentricity that matches calculated and measured temperature differences between the hottest and coldest subchannel effluent temperatures.

Linear interpolations were performed to determine multipliers to match measured and calculated powers at which the maximum wall temperature first exceeded the saturation temperature. The powers for these interpolations were calculated based on both concentric flow channel dimensions and an outer channel eccentricity set to match the spread in computed and measured subchannel effluent temperatures under stable flow conditions.

The multiplier for the wall saturation temperature criterion was based on the calculated results for concentric channels. Table 2 lists the results of these calculations. A wall saturation temperature criterion multiplier of 0.878 was recommended for calculating LOPA ECS addition phase limits. For the four tests analyzed in this report, this is the average value of the multiplier that matches measured and calculated powers at which the maximum wall temperature equals the saturation temperature. The margin between the 
limiting power for this value of the multiplier and the power at thermal excursion is between $15 \%$ and $20 \%$.

Table 2 gives the effect of the wall saturation temperature multiplier on the limit for the ECS addition phase of the LOPA. According to the results in this table, a multiplier of 0.878 would yield a limiting power that is $37 \%$ of historical full power.

\section{Transition between High and Low Flow Rate Criterion}

The wall saturation temperature criterion is applicable only at low flow rates, where the tests have demonstrated that buoyancy-induced flow reversal can occur prior to the onset of flow instability. A Stanton number criterion was retained for use at higher flow rates, where buoyancy effects are not significant. The wall saturation temperature criterion was restricted to Peclet numbers below 70,000, where the Peclet number is defined by

$$
P e=\frac{D_{h} \rho c_{p} G}{k A_{x}}
$$

This value corresponds to the lowest Peclet number tested in benchmarking the LOCA-FI Stanton number criterion $(\mathrm{St}=0.00455)$ [8] and is considerably above the value where buoyancy effects are significant.

The structure of the FLOPA limits code made it easier to specify when to apply the wall saturation temperature criterion in terms of a transient time instead of a Peclet number. Figure 13 depicts variations in the Peclet numbers in the limiting subchannel (located outside the outer fuel tube of the fuel assembly) for a typical LOPA transient. As shown in this figure, the wall saturation temperature criterion takes effect 344 seconds after the start of the LOPA transient, when the DC pump motors flood and the DC pumps begin to coast down. The Peclet number at this time is approximately 70,000 .

\section{Conclusion}

Based on the results of the SPRIHTE rig tests, a wall saturation temperature criterion was recommended for calculating the limit for the ECS addition phase of the LOPA. An analysis of preliminary test results was used to set this limit criterion. This analysis shows that the maximum wall temperature inside the assembly should not exceed 0.878 times the local fluid saturation temperature in degrees $\mathrm{C}$. Use of the criterion with this multiplier set the LOPA core power limit at $37 \%$ of historical full power. 


\section{References}

[1] B. J. Hardy and A. M. White, "A Probabilistic Method for Determining Effluent Temperature Limits for Flow Instability in SRS Reactors (U)," Westinghouse Savannah River Company Report, WSRC-TM-90-5 (DPSTM-160) (1990).

[2] P. Saha and N. Zuber, "Point of Net Vapor Generation and Vapor Void Fraction in Subcooled Boiling," Proceedings, 5th International Heat Transfer Conference, Tokyo, Japan, Vol. 4 (1974).

[3] P. K. Paul and K. L. Barbour, "DEGB LOPA Limit Recommendation for the K-14.1 Subcycle," Westinghouse Savannah River Company Report, WSRC-RP-91-444, Rev. 1 (1992).

[4] B. S. Johnston, "Limits for Stable Downward Flow in a Single Heated Annulus at LOPA Conditions," Westinghouse Savannah River Company Report, NES-ETH-910190 (1991).

[5] H. N. Guerrero and C. M. Hart, "SPRIHTE Prototypic Assembly LOPA Test Data Report," Westinghouse Savannah River Company Report, WSRC-TR-93-012 (1993).

[6] S. E. Aleman, "Documentation of FLOWTRAN for Loss of Pumping Accident Analyses (FLOPA)," Westinghouse Savannah River Company Report, NES-CDG-910133 (1991).

[7] S. E. Aleman, M. V. Gregory, L. L. Hamm, L. D. Koffman, R. E. Pevey, W. H. Reed, and F. G. Smith, "FLOWTRAN: An Algorithm for Describing the Thermal-Hydraulic Behavior of SRP Assemblies (U),"

Westinghouse Savannah River Company Report, DPSTM-140, Rev. 0 (1989).

[8] J. A. Block, C. J. Crowley, F. X. Dolan, R. G. Sam, and B. H. Stoedefalke, "Nucleate Boiling Pressure Drop in an Annulus," Creare, Inc., Technical Note, TN-499, Vol. 1 (1990).

\section{Nomenclature}

$\begin{array}{ll}A_{x} & \text { cross-sectional flow area } \\ c_{p} & \text { fluid heat capacity } \\ D_{h} & \text { hydraulic diameter of coolant channel } \\ G^{\prime} & \text { coolant mass flux } \\ k & \text { fluid thermal conductivity } \\ \mathrm{Pe}^{\prime} & \text { Peclet number } \\ q^{\prime \prime} & \text { surface heat flux } \\ \mathrm{St} & \text { Stanton number } \\ \mathrm{T}_{\text {bulk }} & \text { bulk coolant temperature } \\ \mathrm{T}_{\text {sat }} & \text { fluid saturation temperature } \\ \rho & \text { fluid density }\end{array}$


Table 1. Comparison of Savannah River Fuel Assembly Design and SPRIHTE Rig As-Built Dimensions

Dimension

Inner Target OD

Inner Target Rib Circle

Inner Heater ID

Inner Heater OD

Inner Heater Rib Circle

Outer Heater ID

Outer Heater OD

Outer Target Rib Circle

Outer Target ID
Fuel Assembly Design

4.039

4.989

5.067

5.977

7.272

7.346

8.128

8.204

8.992

SPRIHTE Inner Heater Heated Length

SPRIHTE Outer Heater Heated Length

Fuel Assembly Design Overall Length

Fuel Assembly Design Heated Length
SPRIHTE Min. SPRIHTE Max.

4.039

4.041

4.983

5.057

4.999

5.065

5.977

5.982

7.264

7.353

8.136

8.197

8.954

7.282

7.363

8.141

8.242

8.999

All dimensions are in $\mathrm{cm}$.

376

391

384

378

Table 2. Wall Saturation Temperature Criterion Multipliers That Match Measured and Calculated Powers at Which the Maximum Wall Temperatures First Exceeded Saturation Temperatures, Based on Uncorrected Wall Temperature Measurements

\begin{tabular}{|c|c|c|c|}
\hline $\begin{array}{l}\text { Flow Rate } \\
\text { (L/min) }\end{array}$ & $\begin{array}{l}\text { Inlet Temperature } \\
\left({ }^{\circ} \mathrm{C}\right)\end{array}$ & $\begin{array}{l}\text { Power when } \\
\text { Max. Wall Temp. } \\
\text { = Satn. Temp. (kW) }\end{array}$ & $\begin{array}{l}\text { Wall Saturation } \\
\text { Temp. Criterion } \\
\text { Multiplier }\end{array}$ \\
\hline
\end{tabular}

FLOPA Model with Concentric Flow Channels

$\begin{array}{llll}37.9 & 25 & 127.7 & 0.867 \\ 37.9 & 40 & 105.9 & 0.894 \\ 56.8 & 25 & 188.0 & 0.872 \\ 56.8 & 40 & 152.2 & 0.879 \\ & & & 0.878=\text { average }\end{array}$




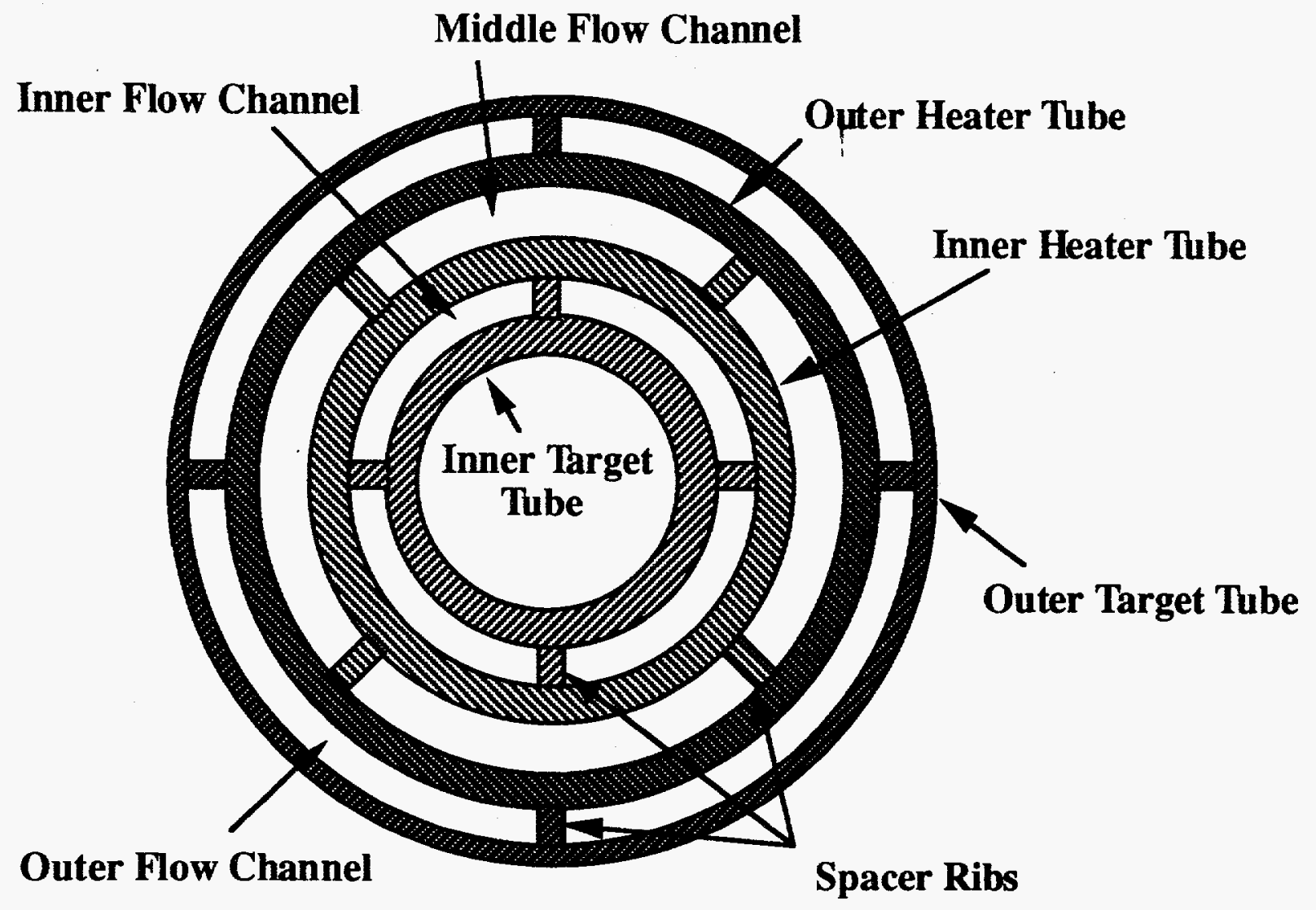

Figure 1. Cross-Sectional View of SPRIHTE Test Rig 


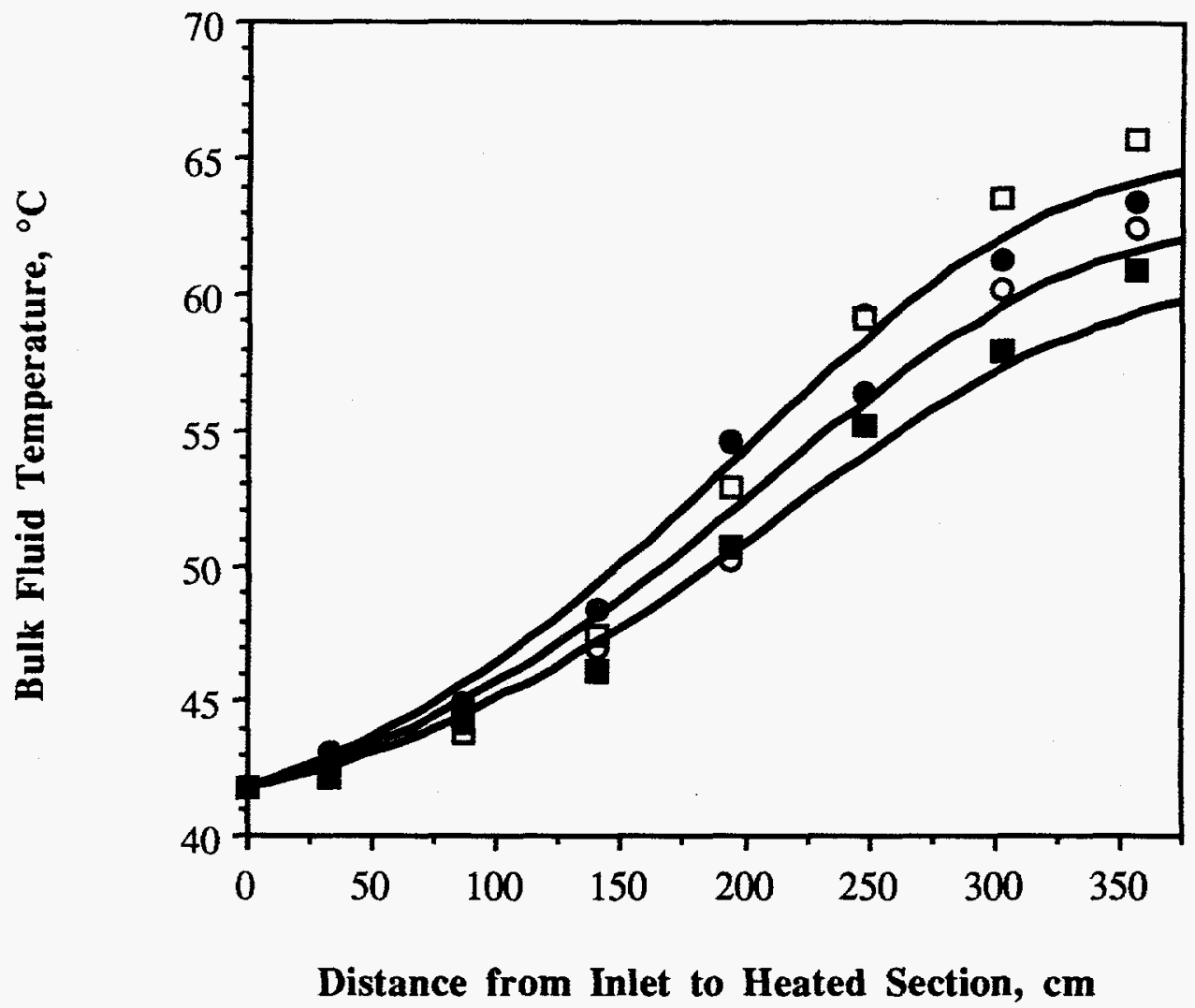

Figure 2. Comparison of Measured and Calculated Subchannel Fluid Temperatures for the Outer Channel at $57 \mathrm{~L} / \mathrm{min}, 40^{\circ} \mathrm{C}$ Inlet, $78 \mathrm{~kW}$

Symbols represent bulk fluid temperature measurements for the four outer subchannels. Lines represent calculated fluid temperatures for these four subchannels. (Calculated temperature profiles for two or more subchannels may coincide because of assumed symmetries in the model.) No correspondence between calculated temperature profiles and specific subchannel measurements is implied. 


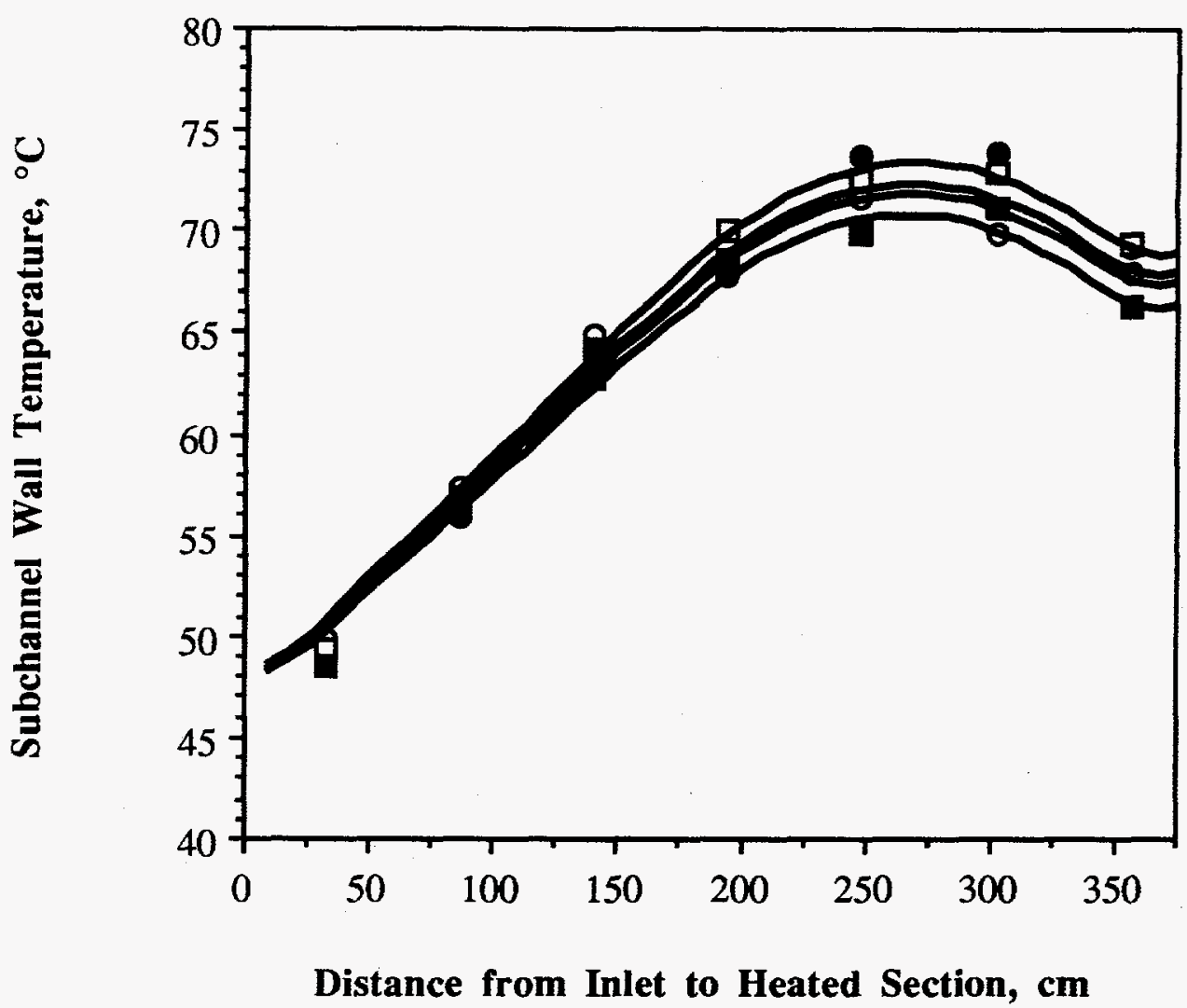

Figure 3. Comparison of Measured and Calculated Outer Heater Wall Temperatures at $57 \mathrm{~L} / \mathrm{min}, 40^{\circ} \mathrm{C}$ Inlet, $78 \mathrm{~kW}$

Symbols represent outer heater wall temperature measurements for the four subchannels. Lines represent calculated outer heater wall temperatures for the four subchannels. (Calculated temperature profiles for two or more subchannels may coincide because of assumed symmetries in the model.) No correspondence between calculated temperature profiles and specific subchannel measurements is implied. 


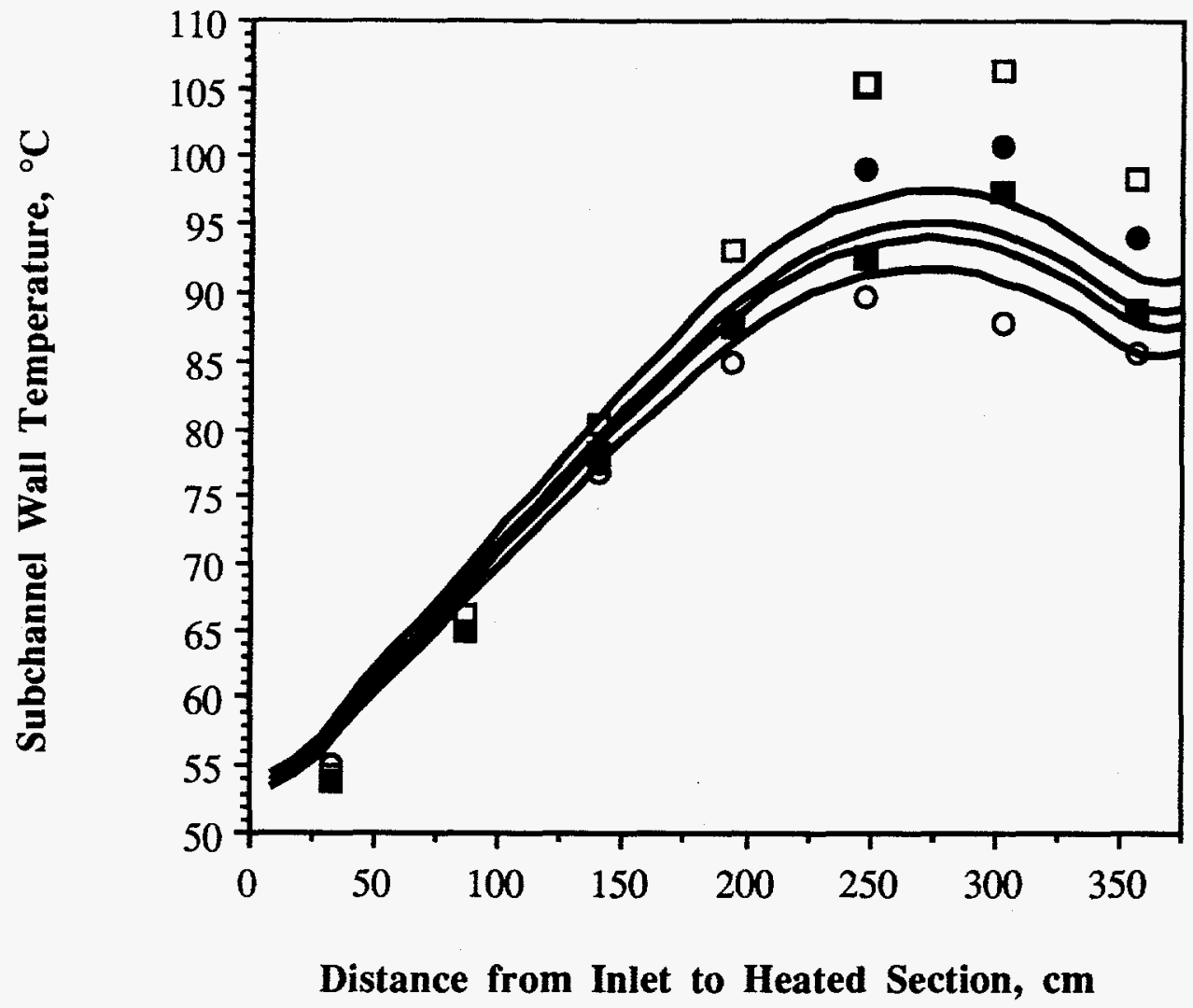

Figure 4. Comparison of Measured and Calculated Outer Heater Wall Temperatures at $57 \mathrm{~L} / \mathrm{min}, 40^{\circ} \mathrm{C}$ Inlet, $142 \mathrm{~kW}$

Symbols represent outer heater wall temperature measurements for the four subchannels. Lines represent calculated outer heater wall temperatures for the four subchannels. (Calculated temperature profiles for two or more subchannels may coincide because of assumed symmetries in the model.) No correspondence between calculated temperature profiles and specific subchannel measurements is implied. 


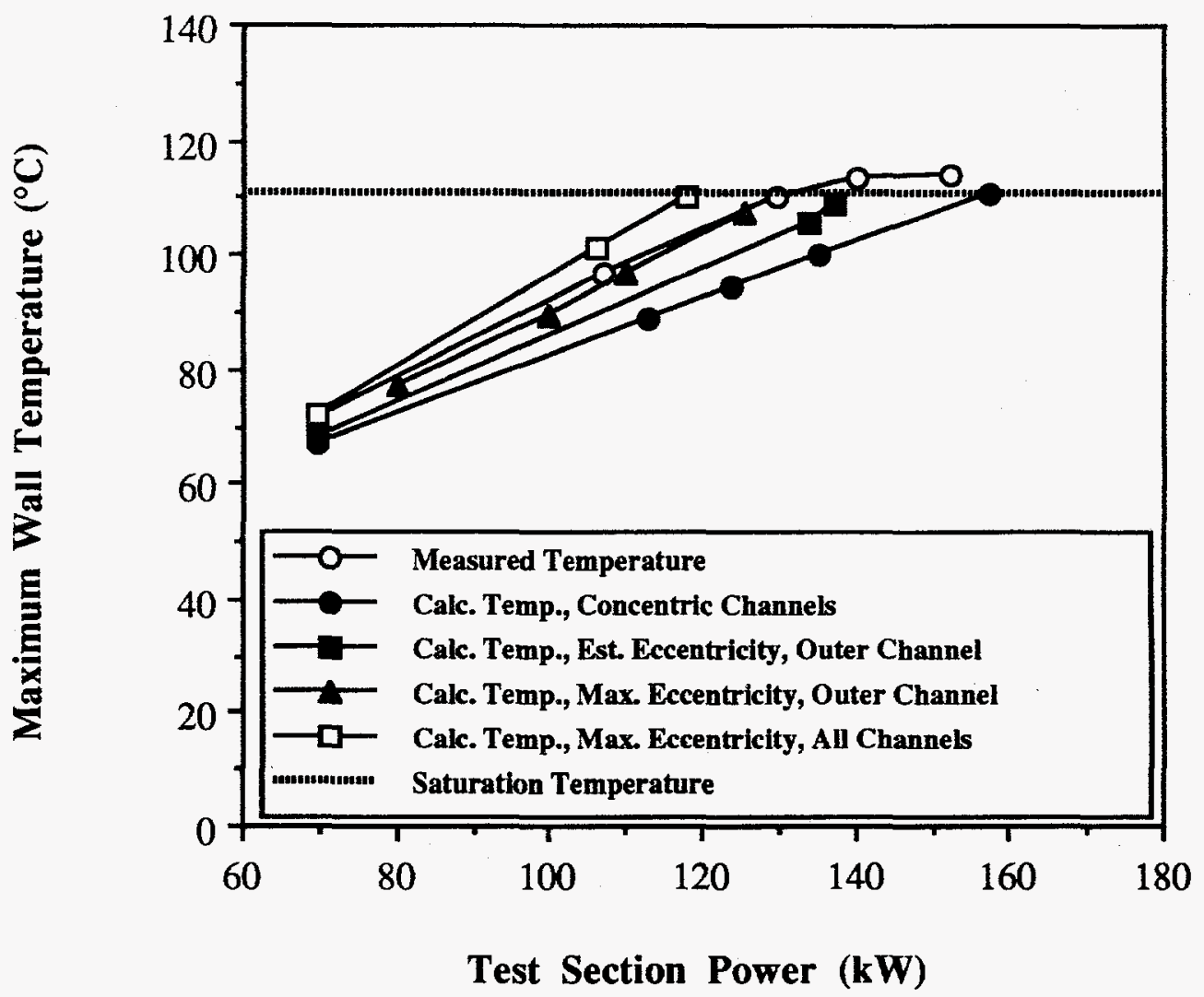

Figure 5. Comparison of Measured and Calculated Maximum Wall Temperatures for the SPRIHTE Tests at $10 \mathrm{gpm}$ and $25^{\circ} \mathrm{C}$ Inlet. 


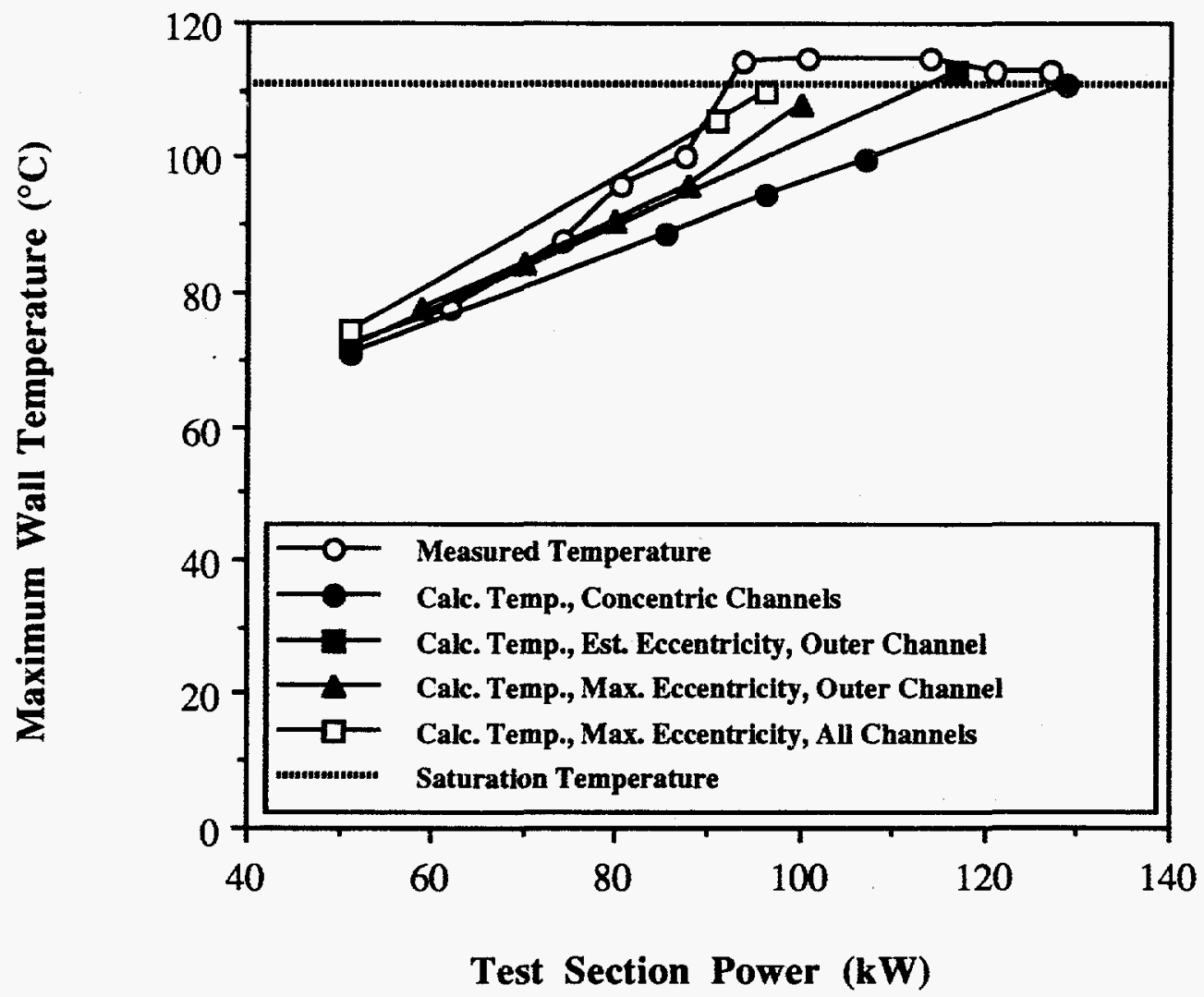

Figure 6. Comparison of Measured and Calculated Maximum Wall Temperatures for the SPRIHTE Tests at $10 \mathrm{gpm}$ and $40^{\circ} \mathrm{C}$ Inlet. 


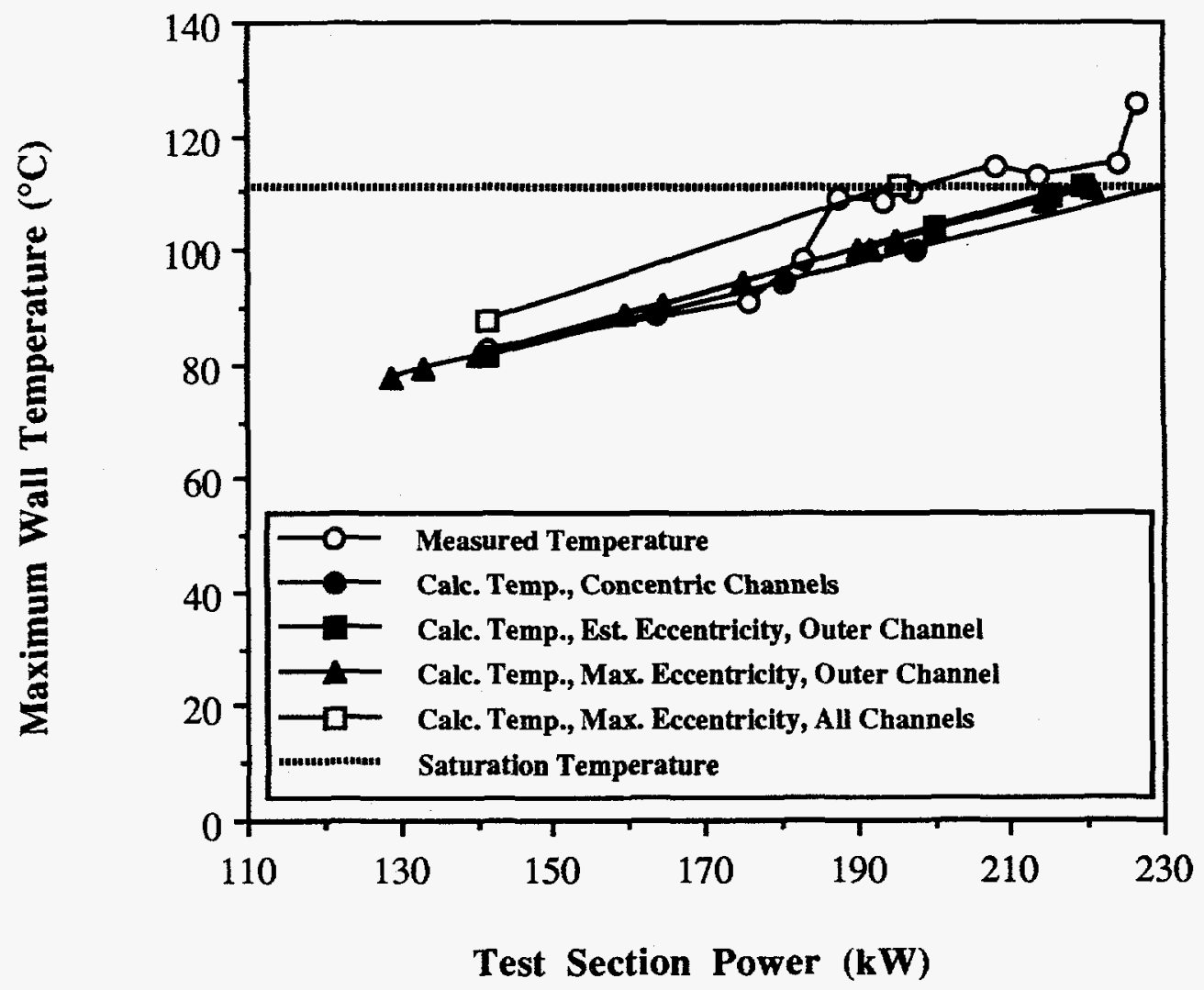

Figure 7. Comparison of Measured and Calculated Maximum Wall Temperatures for the SPRIHTE Tests at $15 \mathrm{gpm}$ and $25^{\circ} \mathrm{C}$ Inlet. 


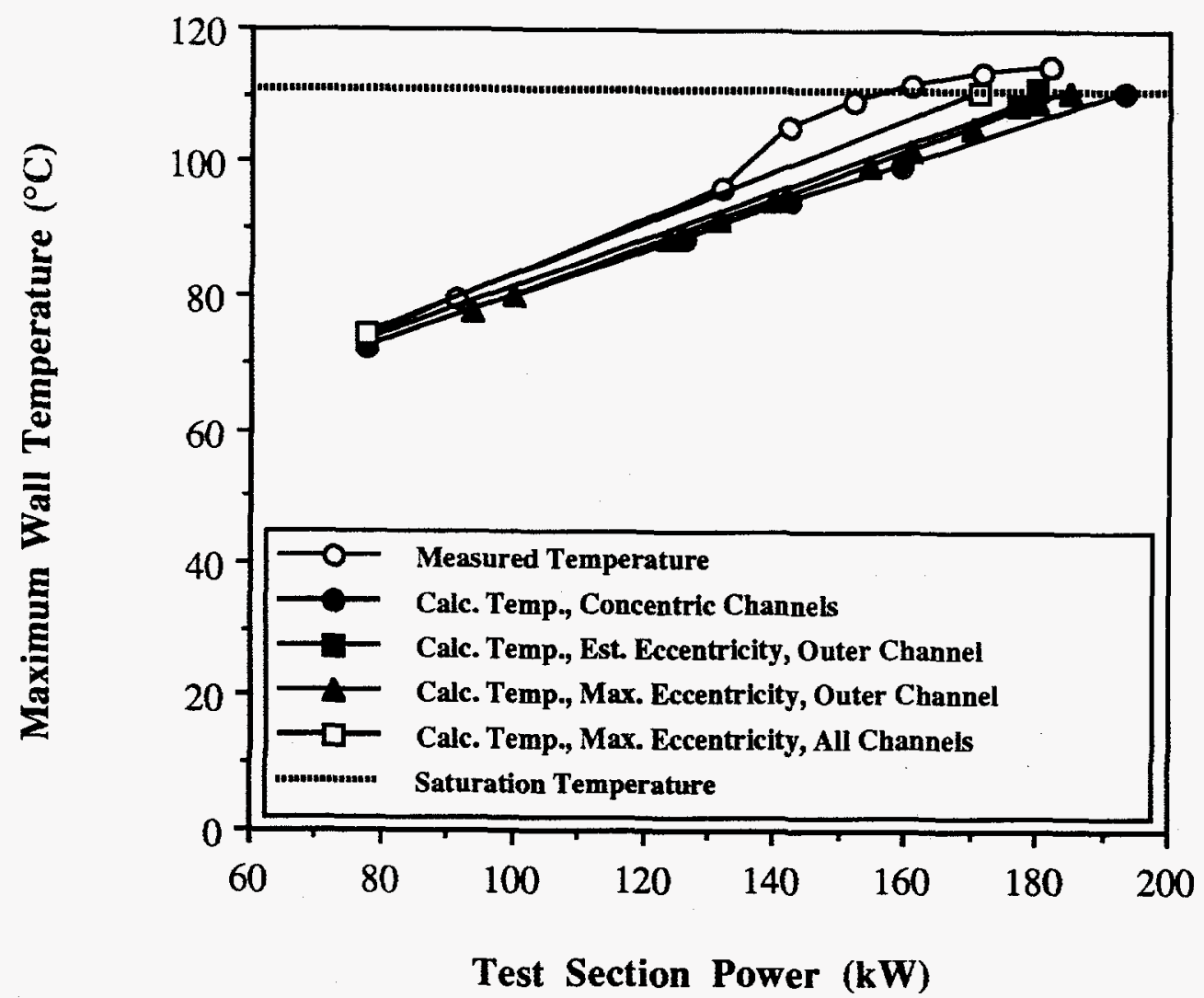

Figure 8. Comparison of Measured and Calculated Maximum Wall Temperatures for the SPRIHTE Tests at $15 \mathrm{gpm}$ and $40^{\circ} \mathrm{C}$ Inlet. 


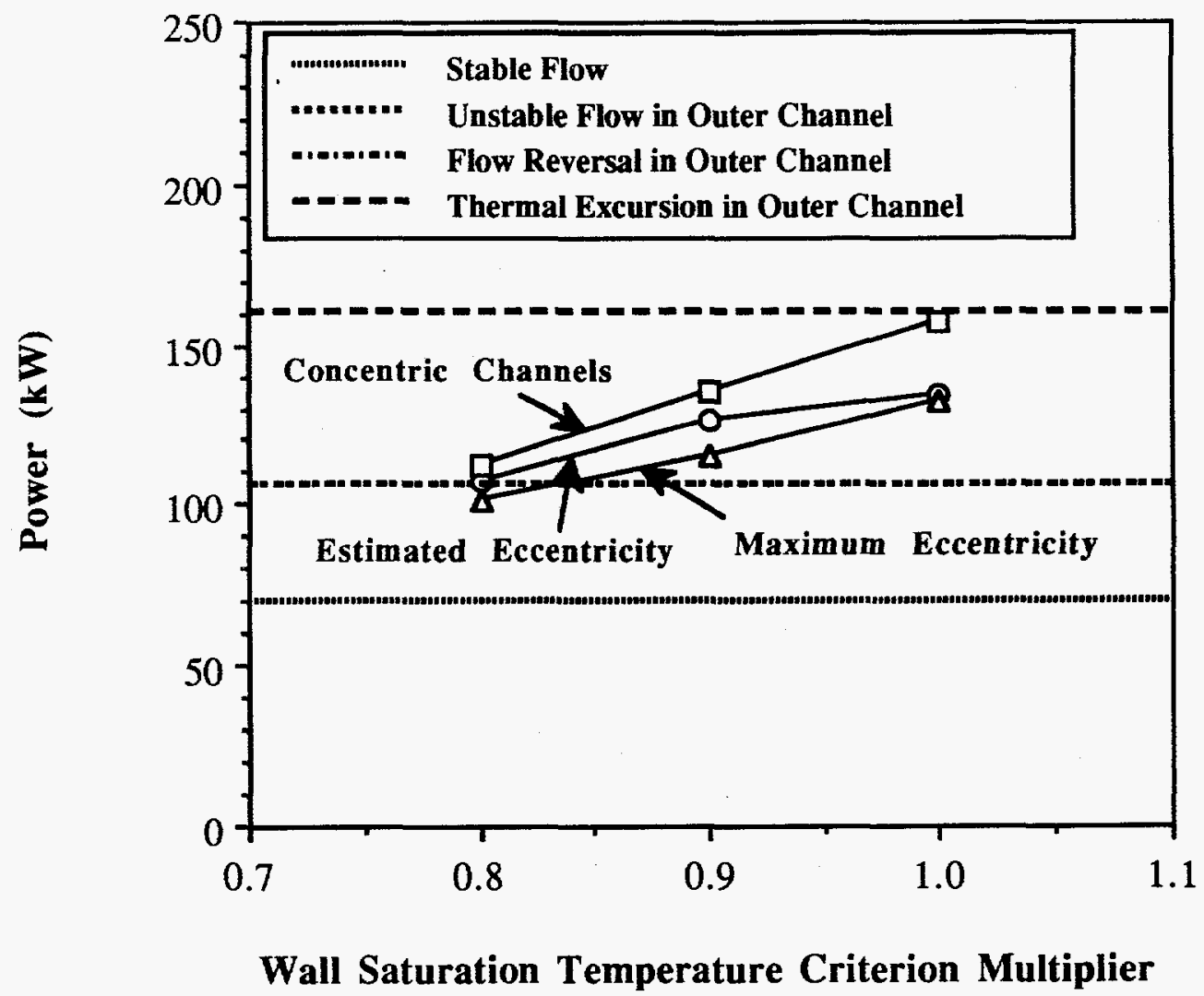

Figure 9. Comparison of Wall Saturation Temperature Criterion Limits with Measured Conditions for the SPRIHTE Tests at $10 \mathrm{gpm}$ and $25^{\circ} \mathrm{C}$ Inlet. 


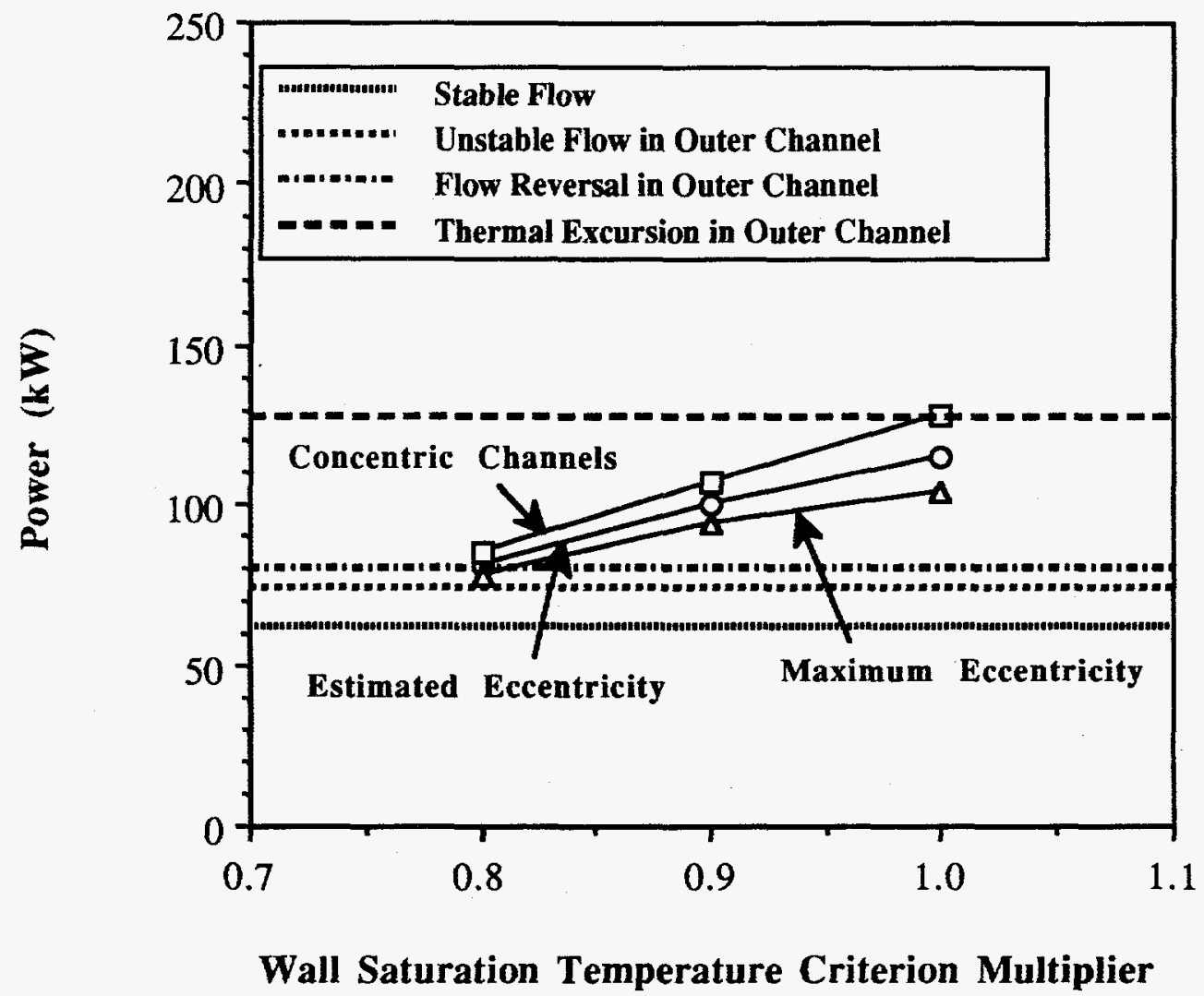

Figure 10. Comparison of Wall Saturation Temperature Criterion Limits with Measured Conditions for the SPRIHTE Tests at $10 \mathrm{gpm}$ and $40^{\circ} \mathrm{C}$ Inlet. 


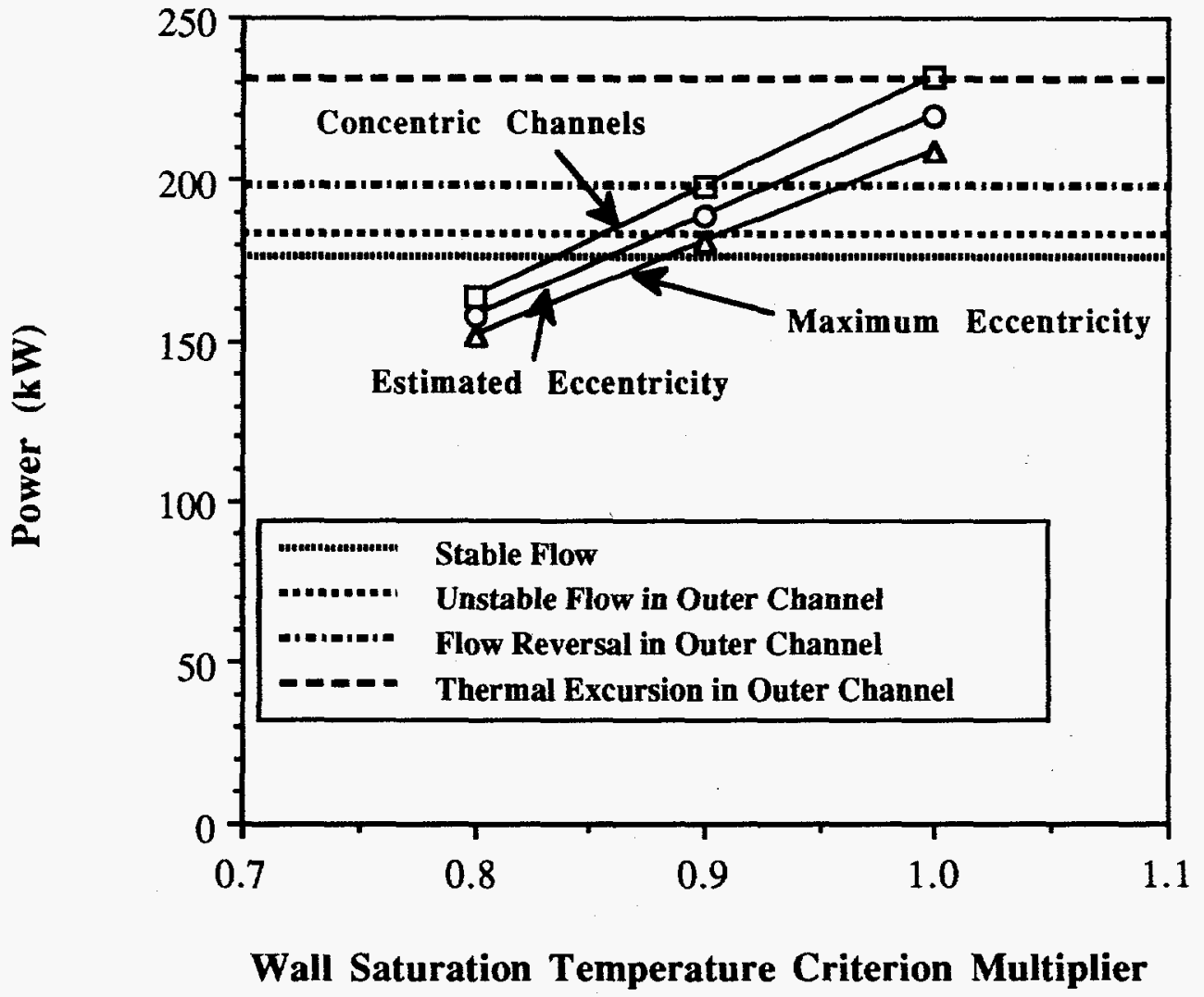

Figure 11. Comparison of Wall Saturation Temperature Criterion Limits with Measured Conditions for the SPRIHTE Tests at $15 \mathrm{gpm}$ and $25^{\circ} \mathrm{C}$ Inlet. 


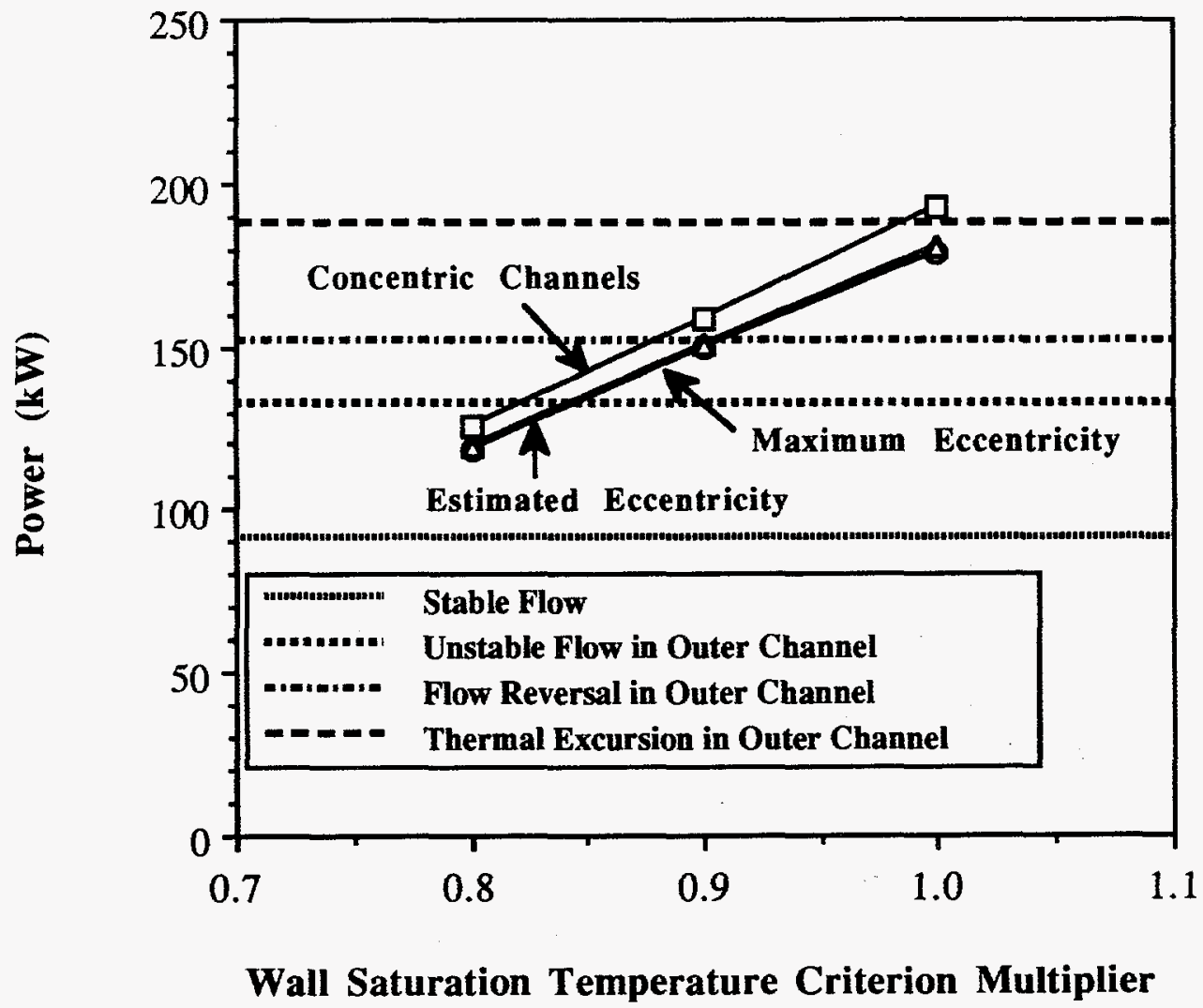

Figure 12. Comparison of Wall Saturation Temperature Criterion Limits with Measured Conditions for the SPRIHTE Tests at $15 \mathrm{gpm}$ and $40^{\circ} \mathrm{C}$ Inlet. 


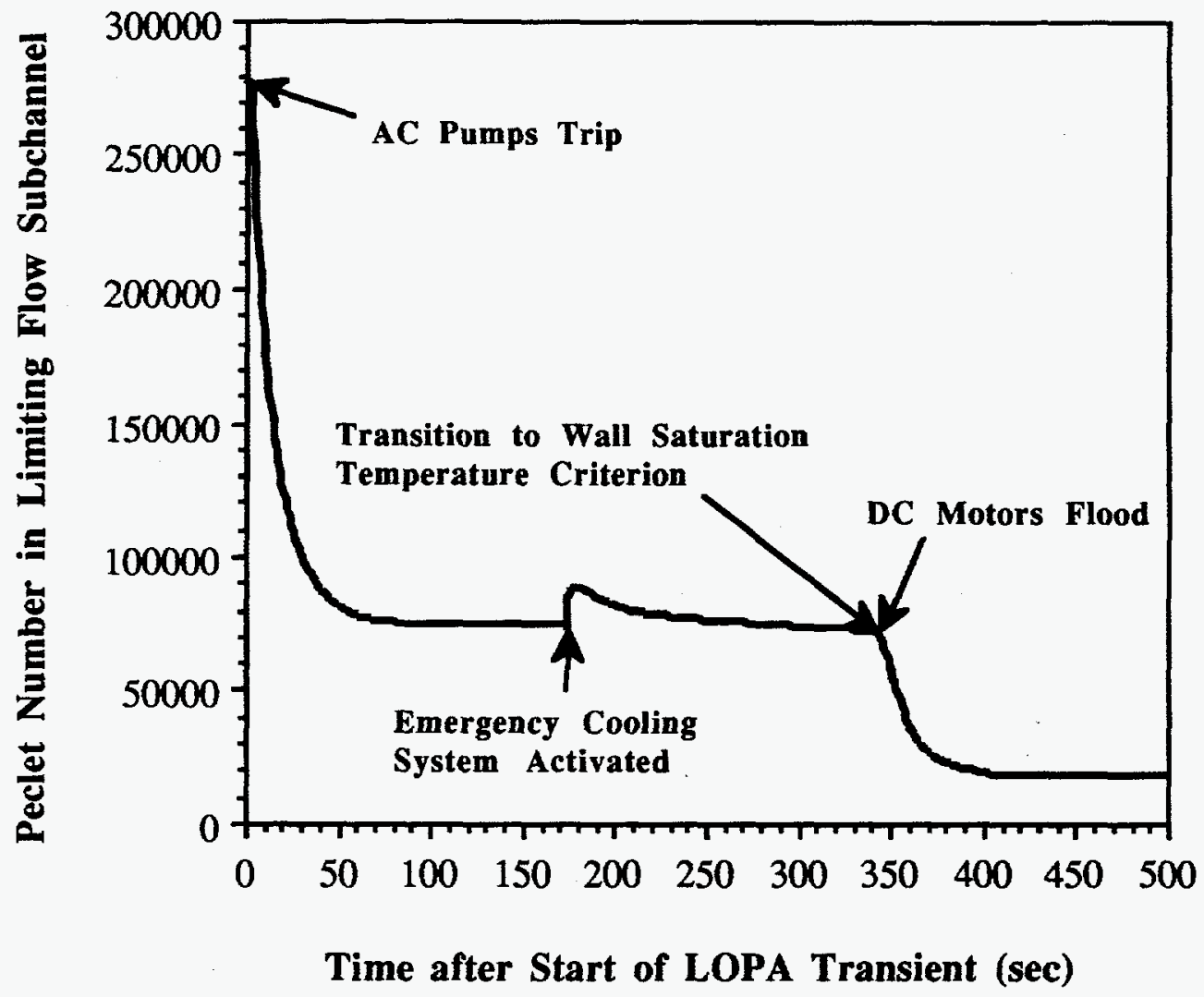

Figure 13. Variation of Peclet Numbers in the Limiting Subchannel during the LOPA Transient 